\title{
Combining the advantages of neural networks using the concept of committee machine in the groundwater salinity prediction
}

\author{
Rahim Barzegar ${ }^{1} \cdot$ Asghar Asghari Moghaddam ${ }^{1}$
}

Received: 21 December 2015/Accepted: 23 December 2015/Published online: 27 January 2016

(C) Springer International Publishing Switzerland 2016

\begin{abstract}
Salinity is one of the main factors in groundwater quality monitoring. The main objectives of this study are to investigate and compare the accuracy of three different neural computing techniques, multi-layer perceptron neural network (MLP), radial basis function neural network (RBFNN), and generalized regression neural network (GRNN), in prediction of groundwater salinity of the Tabriz plain confined aquifer, expressed by electrical conductivity $[\mathrm{EC}(\mu \mathrm{S} / \mathrm{cm})]$, and to employ an integrated method to combine the advantages of neural network models utilizing the concept of committee machine. To develop the models, 93 data records of groundwater samples were collected from East Azarbaijan regional water company. The data set including $\mathrm{Ca}^{2+}, \mathrm{Mg}^{2+}, \mathrm{Na}^{+}, \mathrm{SO}_{4}{ }^{2-}$ and $\mathrm{Cl}^{-}$concentrations as the inputs and salinity [EC $(\mu \mathrm{S} /$ $\mathrm{cm})]$ as an output were divided into two subsets; training and testing based on cross validation approach. After training and testing of the models, the performance of the models were evaluated using root mean square errors (RMSE), determination coefficient $\left(\mathrm{R}^{2}\right)$ and mean absolute error (MAE). The performance criteria of the constructed neural network models showed that RBFNN model has the best performance in predicting salinity. The committee neural network (CNN) combined the results of salinity predicted from MLP, RBFNN and GRNN, each of them has a weight factor showing its contribution in overall prediction. The optimal weights were derived by a genetic algorithm (GA). The results of salinity prediction derived from CNN showed that the CNN performs better than any
\end{abstract}

Rahim Barzegar

rm.barzegar@yahoo.com

1 Department of Earth Sciences, Faculty of Natural Sciences, University of Tabriz, Tabriz, Iran one of the individual ANNs acting alone for predicting groundwater salinity.

Keywords Groundwater salinity prediction - Neural network models · Committee machine $\cdot$ Tabriz plain · Iran

\section{Introduction}

Groundwater is one of the major water resources for domestic, industrial and agricultural uses in arid and semiarid regions worldwide. It is important to monitor and evaluate the quality of any groundwater that may be potentially used for various purposes. Salinity is one of the major hydrochemical parameters to evaluate groundwater quality. Salinity is composed of hundreds of different ions, including chloride $\left(\mathrm{Cl}^{-}\right)$, sodium $\left(\mathrm{Na}^{+}\right)$, nitrate $\left(\mathrm{NO}_{3}{ }^{-}\right)$, calcium $\left(\mathrm{Ca}^{2+}\right)$, magnesium $\left(\mathrm{Mg}^{2+}\right)$, bicarbonate $\left(\mathrm{HCO}_{3}{ }^{-}\right)$, and sulfate $\left(\mathrm{SO}_{4}{ }^{2-}\right)$. Moreover, toxic ions such as boron (B), bromide $\left(\mathrm{Br}^{-}\right)$and iron $(\mathrm{Fe})$ could be accumulated at higher levels (Nasr and Zahran 2014).

Groundwater quality degradation can be caused by natural and anthropogenic processes. The origins of groundwater salinization are diverse such as (1) seawater intrusion (Park et al. 2005; Bouchaou et al. 2008; Custodio 2010; Cruz et al. 2011); (2) evapo-concentration (concentration by evapotranspiration) of airborne salts (Alcalá and Custodio 2008; Guan et al. 2010); (3) hydrogeological characteristics of the aquifer (Ben Moussa et al. 2011; Farber et al. 2007); (4) water-rock interaction, such as dissolution, leaching and hydrolysis of minerals (Van der Weijden and Pacheco 2003; Abid et al. 2011; Jalali 2007) and (5) human influence, such as return flows from irrigated agricultural activities (Oren et al. 2004; Almasri 2007; García-Garizabal and Causape 2011). 
Recently, mathematical, statistical and computational methods to simulate and assess many aquifer water quality parameters have been investigated (Seyyed et al. 2013). It is very important to monitor or predict the salinity by means of cost-effective technologies. In this context, black-box models like artificial neural network (ANN) are very attractive to predict the salinity. The advantages of applying ANNs to water quality simulation are: (1) no physics-based algorithm is required to build the model; therefore, the modeling approach is faster and more flexible than physicsbased modeling approaches in most cases; (2) ANNs can handle non-linear relationship easily and properly; and (3) the expertise and user experiences may be incorporated easily into the model structure (Chang et al. 2010).

ANN models have been broadly applied in water quality in recent years. ANNs have been used to simulate the effect of climate change on discharge and the export of dissolved organic carbon and nitrogen from river basins (Clair and Ehrman 1996), predict salinity of groundwater and rivers (Maier and Dandy 1996; Huang and Foo 2002; Nasr and Zahran 2014; Ravansalar and Rajaee 2015), simulate and forecast residual chlorine concentrations within urban water systems (Rodriguez and Serodes 1998), prediction of arsenic, sulfate and nitrate concentrations in groundwater (Yesilnacar et al. 2008; Yesilnacar et al. 2012; Chang et al. 2010), spatial distribution of groundwater quality (Khashei-Siuki and Sarbazi 2013) and determine the leachate amount from municipal solid waste landfill (Karaca and Ozkaya 2006).

A recent development has targeted to predict groundwater salinity from different parameters using neural network techniques (Maier and Dandy 1996; Nasr and Zahran 2014). However, most previous studies were focused on salinity prediction from a unique type of neural network models. The aims of this study are (1) To predict and compare groundwater salinity of Tabriz plain confined aquifer using MLP, GRNN and RBF neural networks; (2) To combine the three ANN models to improve the accuracy of target prediction using the concept of committee machine.

\section{Materials and methods}

\section{Multi-layer perceptron (MLP)}

MLP is one of the commonly used ANN approach for prediction studies. MLP neural networks structure is made up of one input layer, one output layer, and at least one hidden layer consisting of hidden neurons (Fig. 1). The hidden and output layers consist of some processing elements called neurons. The number of neurons in the hidden layers is usually optimized using the available data through

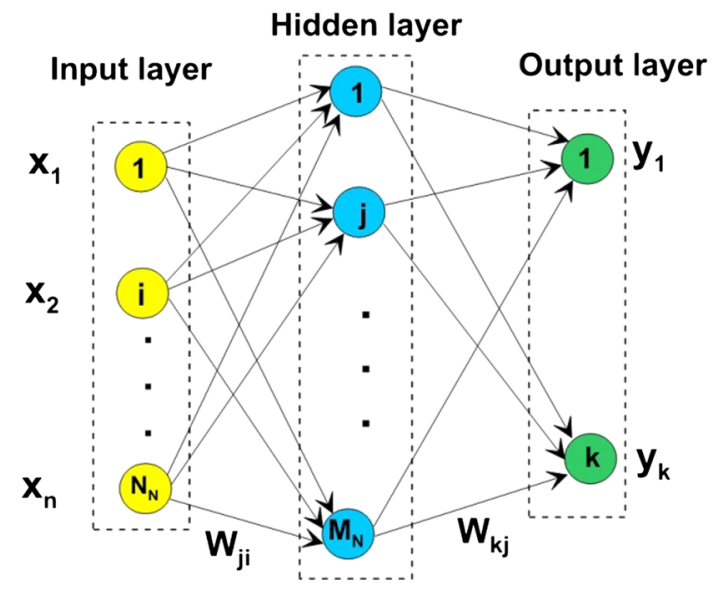

Fig. 1 Schematic diagram of a feed-forward MLP neural network

the use of a trial and error procedure. The calculation in the network is done in hidden and output layers by the connections between all the elements through synaptic weights.

Figure 1 shows the structure of a MLP neural network model. In this Figure $i, j$ and $k$ denote input layer, hidden layer and output layer neurons, respectively, and $w$ is the applied weight by the neuron. The explicit expression for an output value of a three layered MLP is given by Nourani et al. (2013):

$y_{k}=f_{\circ}\left[\sum_{i=1}^{M_{N}} W_{k j} \cdot f_{h}\left(\sum_{i=1}^{N_{N}} W_{j i} X_{i}+W_{j 0}\right)+W_{k 0}\right]$

where $W_{j i}$ is a weight in the hidden layer connecting the $i$ th neuron in the input layer and the $j$ th neuron in the hidden layer, $W_{j 0}$ is the bias for the $j$ th hidden neuron, $f_{h}$ is the activation function of the hidden neuron, $W_{k j}$ is a weight in the output layer connecting the $j$ th neuron in the hidden layer and the $k$ th neuron in the output layer, $W_{k 0}$ is the bias for the $k$ th output neuron, $f_{\circ}$ is the activation function for the output neuron, $X_{i}$ is $i$ th input variable for input layer and $y_{j}$ is computed output variable. $N_{N}$ and $M_{N}$ are the number of the neurons in the input and hidden layers, respectively. The weights are different in the hidden and output layers, and their values can be changed during the network training process. Every neuron in each layer is connected to a neuron of an adjacent layer having different weights. Each neuron receives signals from the neurons of the previous layer weighted by the weighted connections between neurons except in the input layer. Neurons then produce an output signal by passing the summed signal through an activation function (Maqsood et al. 2005; Ghavidel and Montaseri 2014). The gradient descent, conjugate gradient, Levenberg-Marquardt, and etc. learning algorithms can be used for training the MLP model (Kisi et al. 2015). 


\section{Radial basis function neural network (RBFNN)}

Broomhead and Lowe (1988)introduced radial basis function neural networks in late 1980s. RBF networks have the advantage of non-suffering from local minima in the same way as multi-layer perceptrons (Haykin 1994). RBF networks are also good at modeling nonlinear data and can be trained in one stage rather than using an iterative process as in MLP and also learn the given application quickly (Venkatesan and Anitha 2006). Also, an important property of RBF neural networks is that a high-dimensional space nonlinear problem can be easily broken down through a set of combination of radial basis functions, besides they are the beneficiary of the ability to be quickly trained (Chang and Chen 2003).

A radial basis function is represented by a center $U$ where the function value is the maximum (usually 1) and a radius (spread) $\sigma$. The most common choice for the RBFNN is the Gaussian function, in which the center of a hidden node can be specified by the mean (center, $U$ ) and the deviation (spread, $\sigma$ ).

In RBFNN, the hidden layer is self-organizing in which its parameters rely on the distribution of the input vector. The hidden layer nodes compute the distance between their centers and the point on the input set that corresponds to the input vector. For the $p$ th input pattern $X_{P}$, the response of the $j$ th hidden layer node $q_{j}$ is of the following form (Fernando and Jayawardena 1998; Kisi 2009; Kisi et al. 2015):

$q_{j}=f\left\{\frac{\left\|X_{p}-U_{f}\right\|}{2 \sigma_{j}^{2}}\right\}$

where $\|$.$\| usually denotes as the Euclidean norm. The$ output vector of the hidden layer $\left(q_{k}\right)$ is processed by each neuron of the output layer which is usually a summing function.

$y_{k}=\sum_{j=1}^{L} q_{j} W_{k j}$

$W_{k j}$ is the output layer weights. The output layer uses supervised learning (similar to MLP) to set its parameters testing against each of the target vector (actual outputs). Figure 2 shows a schematic diagram of a general RBFNN network.

\section{Generalized regression neural network (GRNN)}

The generalized regression neural network, as proposed by Donald Specht (Specht 1991), falls into the category of probabilistic neural networks. GRNN is a neural network architecture that can solve any function approximation

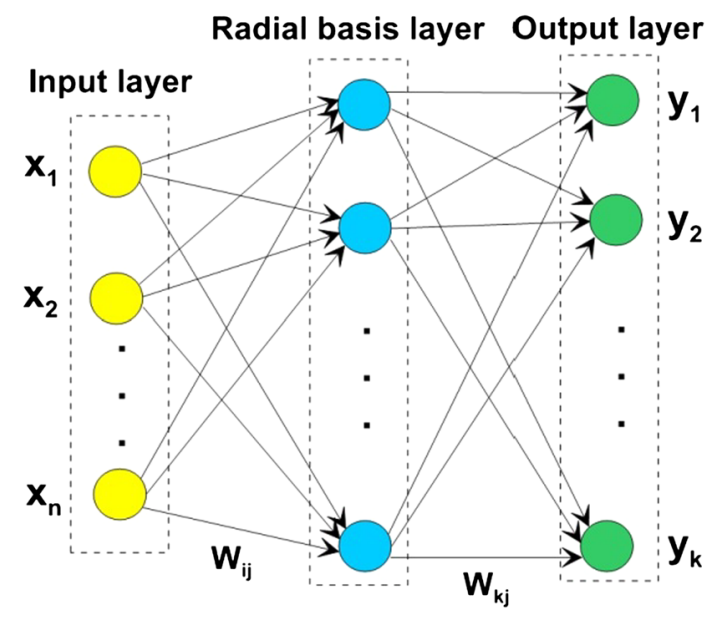

Fig. 2 Schematic diagram of a radial basis function neural network

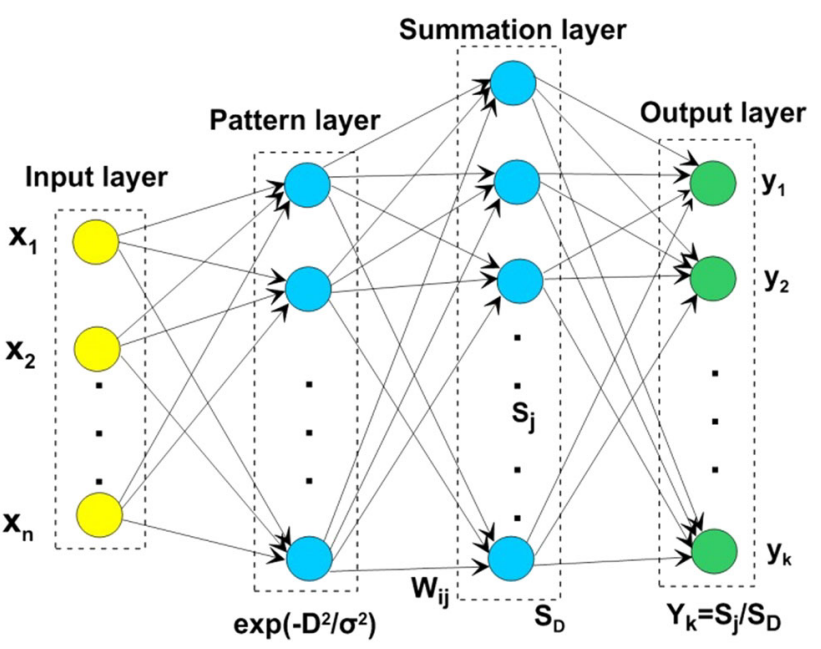

Fig. 3 Schematic diagram of a generalized regression neural network

problem in the sense of estimating a probability distribution function. GRNN is a universal approximator (Park and Sandberg 1991) for smooth functions, allowing it to solve any function approximation and estimate any continuous variable problem when given enough data. This architecture is a one-pass learning algorithm with a highly parallel structure. Even with sparse data in a multidimensional measurement space, the algorithm provides smooth transitions from one observed value to another (Specht 1991).

A schematic of GRNN is illustrated in Fig. 3. As shown in Fig. 3, the GRNN consists of four layers (Patterson 1996): including the input layer, pattern layer, summation layer and output layer. The first layer is fully connected to the second pattern layer through the weights of the pattern layer, where each unit represents a training input pattern and its output is a measure of the distance of the input from the stored patterns. Each pattern layer unit is connected 
with the weights of the summation layer to the two neurons in the summation layer: the S-summation neuron and D-summation neuron. The S-summation neuron computes the sum of the weighted outputs of the pattern layer while the D-summation neuron calculates the unweighted outputs of the pattern neurons. The output layer merely divides the output of each S-summation neuron by that of each D-summation neuron, yielding the predicted value to an unknown input vector $x$ as:

$y=\frac{\sum_{i=1}^{n} W_{i} \exp \left[-D\left(x, x_{i}\right)\right]}{\sum_{i=1}^{n} \exp \left[-D\left(x, x_{i}\right)\right]}$

$x$ is the input vector, $x_{i}$ is the $i$ th case vector, $x_{j}$ is the $j$ th input variable. $W_{i}$ is the weight connecting the $i$ th neuron in the pattern layer to the summation layer. $n$ and $p$ denote the number of training pattern and elements of an input vector, respectively. $D$ is the Gaussian function of the following form:

$D\left(x, x_{i}\right)=\sum_{j=1}^{p}\left(\frac{x_{j}-x_{i j}}{\sigma_{j}}\right)^{2}$

$x_{i j}$ stands for the $j$ th data value in the $i$ th case vector. $\sigma_{j}$ is the smoothing factor for the $i$ th case vector. During the training process, the error is measured by the means of square error (MSE). The training process would be repeated for several/numerous times with different smoothing factors until the network is optimized according to the minimum amount of MSE or a pre-defined threshold value (Kisi et al. 2015).

\section{Committee neural network $(\mathrm{CNN})$}

A committee neural network ( $\mathrm{CNN})$ has a parallel framework that produces a final output by combining the results of individual experts (Haykin 1991; Sharkey 1996). The CNN combines the results of neural networks and so reaps the benefit of all work. Therefore the performance of the CNN model could be better than any individual neural networks (Bagheripour 2014).

Fundamental of committee machine networks were described by Bhatt and Helle (2002), Lim (2005) and Chen and Lin (2006), Kadkhodaie-Ilkhchi et al. (2009) and Ghiasi-Freez et al. (2012). The assumption is that, there are $N$ trained ANNs with output vector $O_{i}$, which are used to predict target vector $T$. The prediction error could be written as:

$e_{i}=O_{i}-T, \quad i=1, \ldots, N$.

The expectation of the squared error for the $i$ th ANN $\left(O_{i}\right)$ is:

$E_{i}=\xi\left[\left(O_{i}-T\right)^{2}\right]=\xi\left[e_{i}^{2}\right], i=1, \ldots, N$
In which $\xi[$.$] is the expectation. The average error for each$ of the ANNs acting alone is:

$E_{\text {avg. }}=\frac{1}{N} \sum_{i=1}^{N} E_{i}=\frac{1}{N} \sum_{i=1}^{N} \xi\left[e_{i}^{2}\right]$

Applying the averaging method, output vector $O_{i}$ of the CNN is:

$O_{C M A I}=\frac{1}{N} \sum_{i=1}^{N} O_{i}$

Therefore, the CNN has the prediction squared-error:

$$
\begin{aligned}
E_{C M A I} & =\xi\left[\left(O_{C M A I}-T\right)^{2}\right]=\xi\left[\left(\frac{1}{N} \sum_{i=1}^{N} O_{i}-T\right)^{2}\right] \\
& =\xi\left[\left(\frac{1}{N} \sum_{i=1}^{N} e_{i}\right)^{2}\right]
\end{aligned}
$$

Considering Cauchy's inequality:

$$
\begin{aligned}
& \left(a_{1} b_{1}+a_{2} b_{2}+\ldots+a_{n} b_{n}\right)^{2} \leq\left(a_{1}^{2}+a_{2}^{2}+\ldots+a_{n}^{2}\right) \\
& \quad \times\left(b_{1}^{2}+b_{2}^{2}+\ldots+b_{n}^{2}\right)
\end{aligned}
$$

Equations (8) and (10) can be extended as below:

$$
\begin{aligned}
E_{C M A I}= & \xi\left[\left(\frac{1}{N} \sum_{i=1}^{N} e_{i}\right)^{2}\right] \\
& =\frac{\xi}{N^{2}}\left(e_{1} \times 1+e_{2} \times 1+\ldots+e_{N} \times 1\right)^{2} \\
E_{\text {avg. }}= & \frac{1}{N} \sum_{i=1}^{N} \xi\left[e_{i}^{2}\right]=\frac{\xi}{N^{2}}\left(e_{1}^{2}+e_{2}^{2}+\ldots+e_{N}^{2}\right) \\
& \times(1+1+\ldots+1) \\
& =\frac{\xi}{N}\left(e_{1}^{2}+e_{2}^{2}+\ldots+e_{N}^{2}\right) \times(N)
\end{aligned}
$$

Now, Cauchy's inequality can be applied to Eqs. (12) and (13):

$$
\begin{gathered}
\frac{\xi}{N^{2}}\left(e_{1} \times 1+e_{2} \times 1+\ldots+e_{N} \times 1\right)^{2} \\
\leq \frac{\xi}{N}\left(e_{1}^{2}+e_{2}^{2}+\ldots+e_{N}^{2}\right) \times(N)
\end{gathered}
$$

By a simple substitution of two sides of Eq. (14), it will be concluded that:

$E_{C M A I} \leq E_{\text {avg. }}$.

This indicates that the error of CNN is less than or equal to the average of all the ANNs (Chen and Lin 2006). A schematic diagram of the developed $\mathrm{CNN}$ is illustrated in Fig. 4. 


\section{Study area}

Tabriz plain is located in the northwest of Iran and covers an area of $700 \mathrm{~km}^{2}$. The plain is part of the Urmia Lake drainage basin and lies between the latitudes of $45^{\circ} 30^{\prime}$ and $46^{\circ} 15^{\prime} \mathrm{N}$ and altitudes $37^{\circ} 56^{\prime}$ and $38^{\circ} 17^{\prime} \mathrm{E}$ (Fig. 5). The study area is surrounded by southern slopes of Mishow and Moro and west Garadug Mountains (north), northern slopes of Sahand Mountain (south), Tabriz city (east) and Urmia Lake salt marsh lands (west). The plain is located on the eastern shore of Urmia Lake. The mean annual temperature and rainfall in the study area are $12.8^{\circ} \mathrm{C}$ and $230.7 \mathrm{~mm}$, respectively.

Fig. 4 Schematic diagram of CNN model
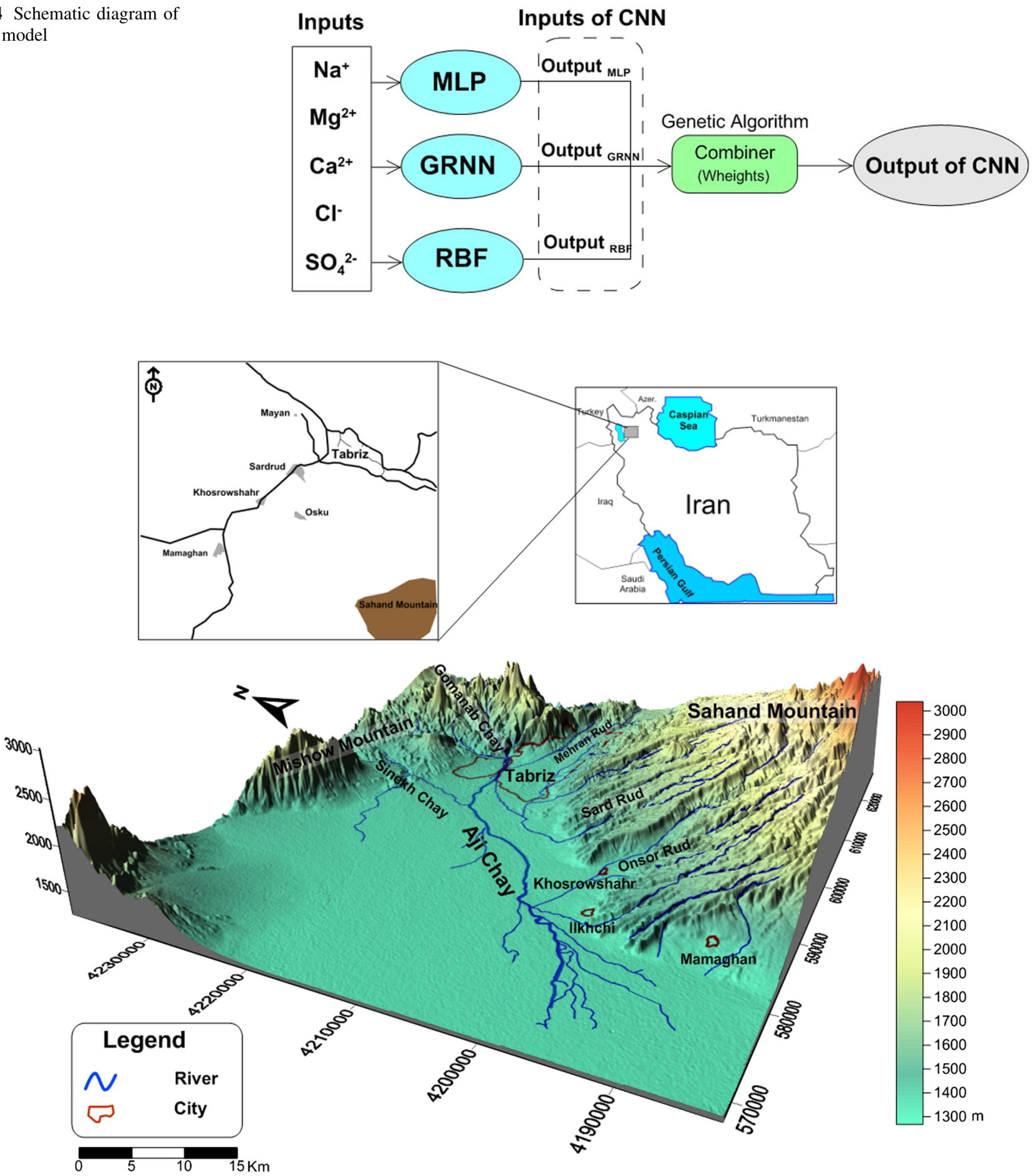

Fig. 5 Location map of the study area 
The land surface elevation represents a more or less uniform geomorphic feature in the plain and regionally the area dipping towards southwest as a result the movement of water from northeast-southwest direction. Variations in elevation are indicative of different land-use patterns and climatological changes.

The geology of the study area is relatively complex. This area includes representative of Devonian to Quaternary age with various movements affecting it, most strongly those of Alpine origin (Asghri Moghaddam 1991). The upper red formation (Miocene series) is widely exposed in the north-eastern part of the Tabriz area, made up of red marls with gypsum, conglomerate, salt and marly limestone's with thickness of up to $1000 \mathrm{~m}$. The PlioPleistocene volcanic tuffs have an extended exposure and overlie the Pliocene beds to the south of the Tabriz plain around the core of the Sahand volcano. The Quaternary Alluvial deposits have their major outcrop in the Tabriz plain. The alluvium, fans and recent Aji Chay terraces consist of several beds of gravel and sand, separated by and grading into silt and clay with thickness of $200 \mathrm{~m}$ (Barzegar et al. 2015).

Tabriz plain has a semi-triangular shape which Mehran Rood River enters to it from east vertices of the triangle and passes inside the Tabriz city and then joins the Aji Chay River at the western end of the city. The Aji Chay River is the most important river in the area that enters to the plain from its northwest boundary, and flows along the central part of the plain towards the west, and at the end of the plain because of very low slope of the ground surface divides into several branches and eventually discharges to the Urmia Lake. These rivers have been deposited alluvial sediments in their paths in the plain. Gomanab Chay and Sinekh Chay Rivers join to the Aji Chay River from right bank side and Sard Rood and Onsor Rood Rivers from left bank side (Fig. 5). These rivers have formed alluvial fans at the entrance of the plain.

The Aji Chay River and its three right bank tributaries, entering the plain from north, crosses the Upper Red formations, as a result, they are transporting fine suspended solids materials during the higher discharges and saline water during the lower discharges periods. Other three left bank side tributaries originated from northern slopes of the Sahand Mountains contain good quality water and depositing coarse sediments in the plain. The Aji Chay River has been deposited alluvial terraces in the central parts of the plain and hydrogeologically divided the plain into southern and northern parts. There is an unconfined aquifer which is extended overall the plain whereas the Aji Chay River course terraces are formed multilayered sediments that the deeper layers contained confined aquifers (Barzegar 2014). Therefore, the central part of the Tabriz plain contains unconfined and confined aquifers while, close to highlands there are only unconfined aquifers (Fig. 6). Maximum thickness of the unconfined aquifer is $100 \mathrm{~m}$ and it decreases to $50 \mathrm{~m}$ toward the central part of the plain (Barzegar et al. 2015). The unconfined aquifer in southern and south eastern part of the area is formed in alluvial fans with good groundwater quality. Aji Chay River terraces are forming multilayer aquifers, but separation of unconfined aquifer from confined aquifers with respect to water quality is occurring at 50-60 m below the ground surface. Groundwater quality above $60 \mathrm{~m}$ depth is saline whereas from 60 to $120 \mathrm{~m}$ it is fresh water (Asghri Moghaddam 1991).

Water resources of the aquifers originate from precipitation, recharges from the rivers, groundwater flow from surrounding mountains, irrigation return flows water, municipal and industrial waste waters. Groundwater flow from the Sahand alluvial tuff aquifer is the main source of water in southern and central parts of the Plain aquifers (Asghri Moghaddam and Allaf Najib 2006; Barzegar et al. 2015). General direction of groundwater flow follows the topography of the area, mainly from northeast to southwest and east to west.

\section{Data collection and preparation}

The data of 93 wells from confined aquifer of Tabriz plain have been used in this study. Data sets such as physicochemical parameters of groundwater samples include electrical conductivity (EC), $\mathrm{pH}$, temperature, $\mathrm{Ca}^{2+}, \mathrm{Mg}^{2+}$, $\mathrm{Na}^{+}, \mathrm{K}^{+}, \mathrm{HCO}_{3}{ }^{-}, \mathrm{CO}_{3}{ }^{2-}, \mathrm{SO}_{4}{ }^{2-}$ and $\mathrm{Cl}^{-}$concentrations were collected by the East Azarbaijan Regional Water Company. These data were measured from 18 September to 16 October 2013. The groundwater of the study area is mainly $\mathrm{Na}^{+}-\mathrm{Cl}^{-}$type. The $\mathrm{pH}$ values of groundwater ranged from 7.0 to 9.2 . The average temperature of the wells was around $17{ }^{\circ} \mathrm{C}$. The EC value in the wells varied between 269 and 12,990 $\mu \mathrm{S} / \mathrm{cm}$, with the average of 3515 $\mu \mathrm{S} / \mathrm{cm}$. The maximum allowable EC value is $1500 \mu \mathrm{S} / \mathrm{cm}$ (WHO 2011). Hence, the groundwater conductivity in most of the observation wells exceeds the maximum allowable value. Descriptive statistics for the collected data is shown in Table 1.

One of the most important steps in developing a prediction model is the selection of the input variables. Because, these variables determine the structure of the ANN model and influence the weighted coefficient and the results of the model. For selection of neural networks inputs, it was tried to choose some variables that are related to salinity $[\mathrm{EC}(\mu \mathrm{S} / \mathrm{cm})]$. For this purpose, Pearson correlation was used (Table 2). Variables with very small correlation coefficients indicate that they have very weak correlations with EC, and thus these variables could be ignored during modeling. $\mathrm{Ca}^{2+}, \mathrm{Mg}^{2+}, \mathrm{Na}^{+}, \mathrm{SO}_{4}{ }^{2-}$ and 
Fig. 6 Schematic positions of aquifer types and location of the sampling wells in the study area

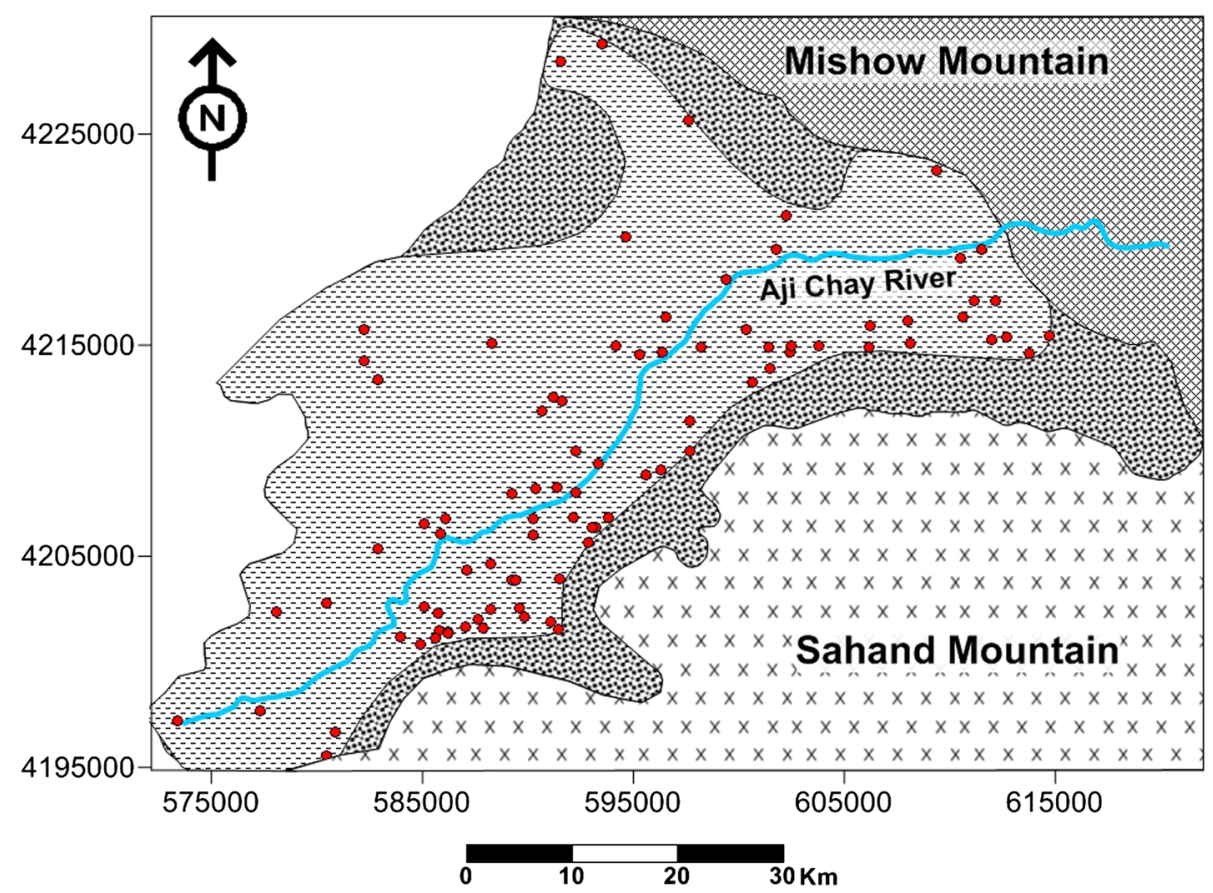

Legend

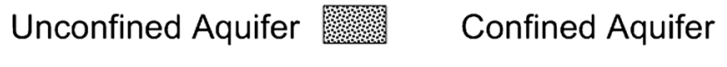

Sampling locations

Table 1 Descriptive statistics for the collected groundwater samples

\begin{tabular}{|c|c|c|c|c|c|c|c|}
\hline & Minimum & Maximum & Mean & SD & Variance & Skewness & Kurtosis \\
\hline $\mathrm{EC}(\mu \mathrm{S} / \mathrm{cm})$ & 269.00 & $1.299 \times 10^{4}$ & $3.515 \times 10^{3}$ & $2.41 \times 10^{3}$ & $5.81 \times 10^{6}$ & 1.30 & 2.37 \\
\hline $\mathrm{pH}$ & 7.00 & 9.20 & 8.2570 & 0.45 & 0.203 & -0.42 & 0.00 \\
\hline Temp. $\left({ }^{\circ} \mathrm{C}\right)$ & 14.00 & 19.00 & 16.78 & 1.41 & 2.01 & 0.02 & -0.963 \\
\hline $\mathrm{Ca}^{2+}\left(\right.$ meq. $\left.\mathrm{L}^{-1}\right)$ & 1.28 & 58.00 & 9.86 & 9.64 & 92.97 & 2.22 & 6.57 \\
\hline $\mathrm{Mg}^{2+}$ (meq. $\mathrm{L}^{-1}$ ) & 0.68 & 28.00 & 7.09 & 4.50 & 20.27 & 1.40 & 3.83 \\
\hline $\mathrm{Na}^{+}$(meq.L $\mathrm{L}^{-1}$ ) & 0.62 & 69.00 & 17.95 & 15.25 & 232.74 & 1.27 & 1.14 \\
\hline $\mathrm{K}^{+}\left(\right.$meq. $\left.\mathrm{L}^{-1}\right)$ & 0.05 & 0.68 & 0.27 & 0.13 & 0.01 & 0.46 & -0.12 \\
\hline $\mathrm{HCO}_{3}{ }^{-}\left(\right.$meq. $\left.\mathrm{L}^{-1}\right)$ & 1.35 & 9.95 & 4.62 & 1.81 & 3.30 & 0.62 & 0.24 \\
\hline $\mathrm{CO}_{3}^{2-}$ (meq.. $\left.{ }^{-1}\right)$ & 0.00 & 0.50 & 0.20 & 0.18 & 0.03 & 0.09 & -1.54 \\
\hline $\mathrm{Cl}^{-}$(meq. $\mathrm{L}^{-1}$ ) & 0.45 & 112.50 & 24.46 & 22.14 & 490.26 & 1.35 & 2.29 \\
\hline $\mathrm{SO}_{4}{ }^{2-}$ (meq.. $\left.\mathrm{L}^{-1}\right)$ & 0.10 & 13.80 & 5.81 & 3.14 & 9.88 & 0.51 & 0.22 \\
\hline
\end{tabular}

$\mathrm{Cl}^{-}$concentrations were selected as inputs and salinity [EC $(\mu \mathrm{S} / \mathrm{cm})]$ as an output to develop the models.

Normalization of data ensures fast processing and convergence during training and minimizes prediction error (Rojas 1996). The input and output data (raw data) were normalized before subjecting to training and testing by transforming the data to the range of 0 to 1 using the Eq. (16);
$\hat{X}=\frac{X-X_{\min }}{X_{\max }-X_{\min }}$.

When the neural networks training completed, the value of the networks output is normalized and it needs denormalization transforming into the actual value. The equation is defined as follows (Eq. 17):

$X=\hat{X} \times\left(X_{\max }-X_{\min }\right)+X_{\min }$ 
Table 2 Pearson correlation to select the input parameters of the ANN models

\begin{tabular}{|c|c|c|c|c|c|c|c|c|c|c|c|}
\hline & EC & $\mathrm{pH}$ & Temp. & $\mathrm{Na}^{+}$ & $\mathrm{K}^{+}$ & $\mathrm{Ca}^{2+}$ & $\mathrm{Mg}^{2+}$ & $\mathrm{HCO}_{3}{ }^{-}$ & $\mathrm{CO}_{3}{ }^{2-}$ & $\mathrm{Cl}^{-}$ & $\mathrm{SO}_{4}{ }^{2-}$ \\
\hline EC & 1 & & & & & & & & & & \\
\hline $\mathrm{pH}$ & -0.377 & 1 & & & & & & & & & \\
\hline Temp. & 0.335 & -0.153 & 1 & & & & & & & & \\
\hline $\mathrm{Na}^{+}$ & 0.862 & -0.204 & 0.553 & 1 & & & & & & & \\
\hline $\mathrm{K}^{+}$ & 0.381 & -0.272 & 0.393 & 0.316 & 1 & & & & & & \\
\hline $\mathrm{Ca}^{2+}$ & 0.739 & -0.471 & 0.079 & 0.308 & 0.254 & 1 & & & & & \\
\hline $\mathrm{Mg}^{2+}$ & 0.860 & -0.331 & 0.295 & 0.580 & 0.404 & 0.771 & 1 & & & & \\
\hline $\mathrm{HCO}_{3}{ }^{-}$ & 0.127 & -0.174 & 0.177 & 0.145 & 0.483 & -0.007 & 0.202 & 1 & & & \\
\hline $\mathrm{CO}_{3}{ }^{2-}$ & -0.217 & 0.766 & -0.167 & -0.234 & -0.204 & -0.507 & -0.365 & -0.137 & 1 & & \\
\hline $\mathrm{Cl}^{-}$ & 0.990 & -0.327 & 0.420 & 0.865 & 0.312 & 0.721 & 0.832 & 0.034 & -0.391 & 1 & \\
\hline $\mathrm{SO}_{4}^{2-}$ & 0.647 & -0.541 & 0.304 & 0.445 & 0.450 & 0.614 & 0.651 & 0.174 & -0.427 & 0.552 & 1 \\
\hline
\end{tabular}

where $X$ is original value, $X_{\min }$ and $X_{\max }$ are minimum and maximum values in the series, respectively, and $\hat{X}$ is the normalized data.

The training/testing data split can have a significant impact on the results of the models. The cross-validation technique (Chang et al. 2013; Fijani et al. 2013) was used in this study to divide the data sets. Based on this approach, 93 data points were divided in two sets; training and testing. The $75 \%$ (70 samples) and $25 \%$ (23 samples) of data were used for training and testing, respectively.

\section{Performance criteria}

The performance of the simulation of training and testing sets was evaluated by following measures of goodness-offit: the coefficient of determination $\left(\mathrm{R}^{2}\right)$, root mean squared error (RMSE) and mean absolute relative error (MARE) shown in Eqs. $(18,19,20)$, respectively. The $\mathrm{R}^{2}$ express the degree of the relation when two variables are linearly related. If $\mathrm{R}^{2}$ is close to 1 , there is good correlation between the dependent and independent variables.

$R^{2}=\left[\sum_{i=1}^{N}\left(P_{i}-\bar{P}\right)\left(O_{i}-\bar{O}\right)\right]^{2}\left[\sum_{i=1}^{N}\left(P_{i}-\bar{P}\right)^{2}\left(O_{i}-\bar{O}\right)^{2}\right]^{-1}$

$R M S E=\left[N^{-1} \sum_{i=1}^{N}\left(P_{i}-O_{i}\right)^{2}\right]^{0.5}$

$M A R E=\frac{1}{N} \sum_{i=1}^{N}\left|\frac{O_{i}-P_{i}}{O_{i}}\right| \times 100$ where $N$ is the number of observations, $P_{i}$ is the predicted values, $O_{i}$ is the observed data, and $\bar{P}$ and $\bar{O}$ are the mean values for $P_{i}$ and $O_{i}$, respectively.

\section{Model development}

This study employed three ANNs include MLP, GRNN and RBFNN to predict the salinity $[\mathrm{EC}(\mu \mathrm{S} / \mathrm{cm})]$ of the Tabriz plain confined aquifer. At the first model, a three layer network as a multilayer perceptron network (MLP) with Levenberg-Marquardt algorithm was used for prediction of groundwater salinity values. Researchers employed the Levenberg-Marquardt algorithm which is an approximation to Newton's method for adjusting the weights of the ANN model because it is more powerful than the conventional gradient descent techniques (Kisi 2007; Kolay and Baser 2014; Nadiri et al. 2014; Tayfur et al. 2014). Five input variables used in the first layer. The number of neurons in the hidden layer which was determined via trial and error method was three and in the output layer one neuron was included groundwater salinity $[\mathrm{EC}(\mu \mathrm{S} / \mathrm{cm})]$ as the target. The transfer function from layer one to two was TANSIG and from layer two to layer three was PURELIN. The performance plot shows the value of the function, in terms of training, validation behaviors, versus the iteration number (Fig. 7). The best validation performance, based on the mean square error, was 0.00032031 at epoch 5 . When the training of the model was completed, the testing data were input to the model and the predicted salinity values were calculated.

The radial basis function neural network (RBFNN) was employed to construct the second model. RBFs are 


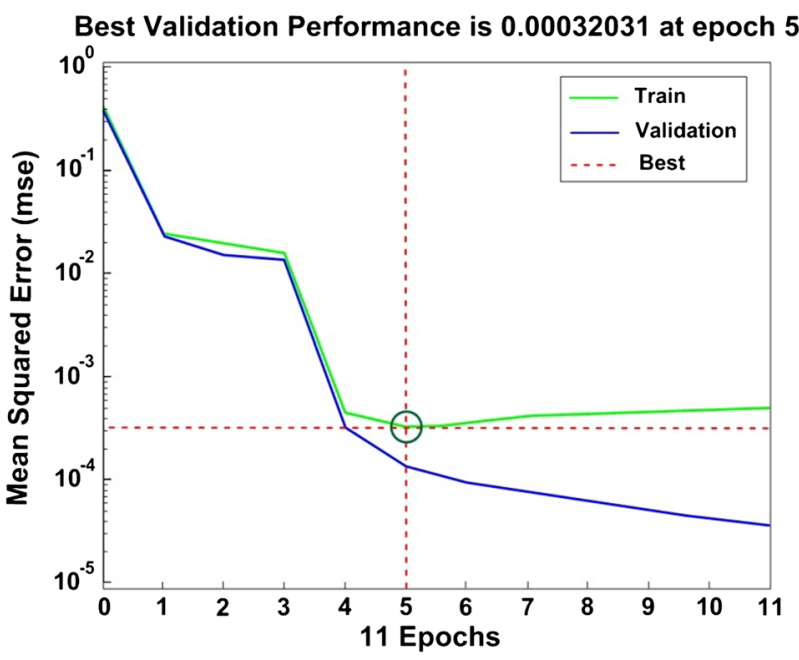

Fig. 7 Training state and performance of the generated MLP neural network model

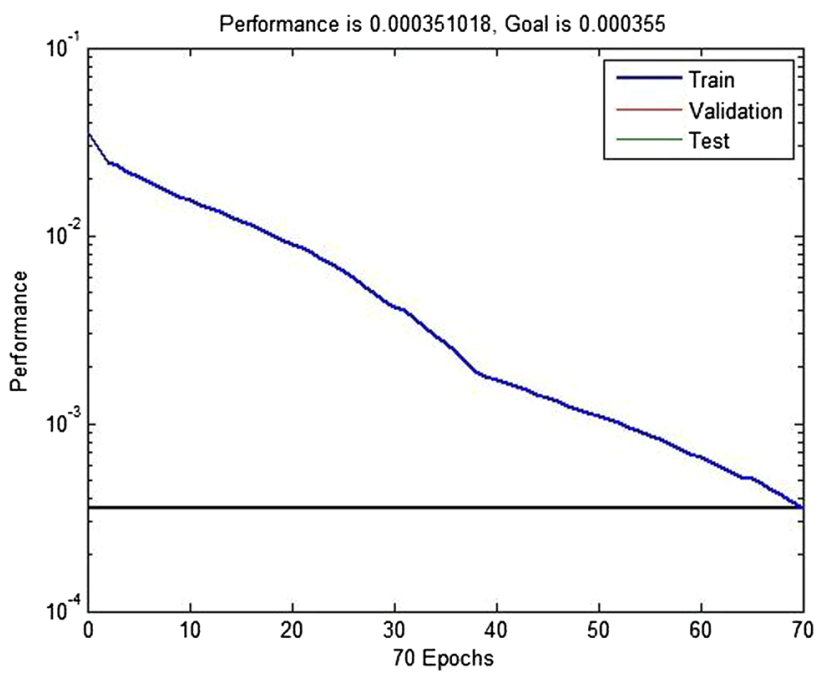

Fig. 8 The MSE of training data during the RBFNN learning period

embedded in a two-layer neural network, where each hidden unit implements a radial-activated function. The output units implement a weighted sum of hidden unit outputs. The input into an RBF network is nonlinear while the output is linear. Radial neurons were added successively to the hidden layer until the desired performance was achieved. Figure 8 shows by inserting 70 neurons that the MSE of the RBF model falls beneath the desired MSE and the training process stops. After training the RBFNN, the testing data were input to the model and the salinity predicted.

A generalized regression neural network (GRNN) is a variation of the radial basis neural networks, which is based on kernel regression networks (Cigizoglu and Alp 2006;

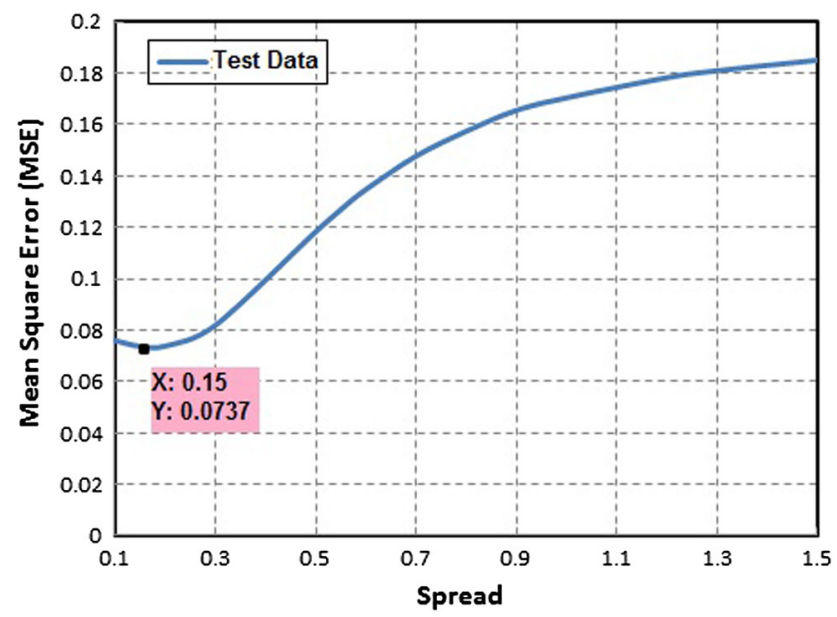

Fig. 9 The RMSE-spread constant graph for the GRNN model

Celikoglu and Cigizoglu 2007). In GRNN model, the key parameter, including the spread factor, plays a crucial role in establishing a good ANN regression model with high prediction accuracy and stability. Different spread factor values between 0.1 and 1.5 were tried for the GRNN model and the optimal one that gave the minimum RMSE in the validation period were selected. The MSE-spread constant graph for the GRNN model is shown in Fig. 9. By specification of 0.15 for the spread factor, the performance of the model reaches its minimum value, 0.0737 .

The proposed CNN integrates the results of the MPL, RBFNN, and GRNN models using a genetic algorithm (GA) to obtain the optimal contribution of the combiner weights. The CNN gains the advantages of each individual ANN and improves the accuracy of prediction procedure. The fitness function that should be optimized with GA is defined as below:

$M S E_{C N N}=\frac{1}{N} \sum_{i=1}^{m}\left(W_{1} \times P_{1 i}+W_{2} \times P_{2 i}+W_{3} \times P_{3 i}-T_{i}\right)^{2}$

where $T_{i}$ is the measured salinity [EC $\left.(\mu \mathrm{S} / \mathrm{cm})\right]$ and $N$ is the number of training data. $W_{1}, W_{2}$ and $W_{3}$ are the weight factors corresponding to the outputs of $P_{1 i}, P_{2 i}$ and $P_{3 i}$, respectively. The sum of the $\mathrm{CNN}$ weights must be equal to one.

To determine the optimal contribution of the weights, the GA parameters were set as follows: The initial population size and initial range were 20 and $[0,1]$, respectively. The crossover and mutation functions were selected as scattered and Gaussian, respectively. The maximum number of the generations that specifies the maximum number of GA iterations was set to 100 . After 100 generations, the variation of the fitness function was insignificant 
and the GA derived values for $W_{1}, W_{2}$ and $W_{3}$ were 0.372 , 0.508 and 0.12 , respectively. The weights obviously represent the individual contribution of each model in construction of the CNN. After running the GA, the optimized weight coefficients were applied to the testing data and the final output was calculated as below:

$$
\begin{aligned}
\text { Salinity }_{C N N}= & 0.372 \times \text { Salinity }_{M L P}+0.508 \\
& \times \text { Salinity }_{R B F N N}+0.12 \times \text { Salinity }_{G R N N} .
\end{aligned}
$$

By applying the capabilities of the GA, the outputs of the individual ANNs were combined.

\section{Results}

The accuracy comparison of MLP, RBFNN, GRNN and CNN models is employed in this part of the study. The results of the developed models are given in Table 3. The RMSE, $\mathrm{R}^{2}$ and MARE values of the MLP model in training step were $171.02 \mu \mathrm{S} / \mathrm{cm}, 0.995$ and $11.38 \%$, respectively. The RMSE, $\mathrm{R}^{2}$ and MARE of the MLP model in the testing step were $447.22 \mu \mathrm{S} / \mathrm{cm}, 0.971$ and $9.5 \%$, respectively.

The RMSE, $\mathrm{R}^{2}$ and MARE values of the RBFNN model in training step were $168.66 \mu \mathrm{S} / \mathrm{cm}, 0.995$ and $6.06 \%$, respectively. The RMSE, $\mathrm{R}^{2}$ and MARE values of the RBFNN model in the testing step were $342.5 \mu \mathrm{S} / \mathrm{cm}, 0.985$ and $8.71 \%$, respectively. The RMSE, $\mathrm{R}^{2}$ and MARE of the GRNN model in the training step were $270.65 \mu \mathrm{S} / \mathrm{cm}$, 0.9877 and $15.22 \%$, respectively. The RMSE, $\mathrm{R}^{2}$ and MARE of the GRNN model in the testing step were 938.01 $\mu \mathrm{S} / \mathrm{cm}, 0.929$ and $12.45 \%$, respectively. Figure 10a-c show the plots between measured and predicted values of the salinity in testing sets for the MLP, RBFNN and GRNN models. It can be seen from these figures, for the testing phase, that the RBFNN model is closer to the exact fit line than the MLP and GRNN models.

It is obvious from the Table 3 that the MLP, GRNN and RBFNN model performances are in general, accurate and reliable. The high accuracy of the developed models can be due to the high correlation of the inputs and output of the models. It is noted that the reliability of MLP, GRNN and
RBFNN models depend on data structure used in training and testing processes and model structure. In ANN predicting models, model performance is influenced by input structure and many training parameters selected by trial and error method (Firat and Gungor 2009). Therefore, these parameters should be carefully selected.

The RMSE, $\mathrm{R}^{2}$ and MARE of the CNN model in the training step were $129.94 \mu \mathrm{S} / \mathrm{cm}, 0.9972$ and $5.51 \%$, respectively. The RMSE, $\mathrm{R}^{2}$ and MARE values of the CNN model in the testing step were $317.86 \mu \mathrm{S} / \mathrm{cm}, 0.9908$ and $4.38 \%$, respectively (Fig. 10d). The performance of the CNN shows improvement in comparison with the individual ANNs acting alone for predicting salinity. Actually, the GA decreased the contribution of the poorly performing experts and increased the weight of the high performance experts for final prediction of the output by $\mathrm{CNN}$.

\section{Conclusion}

In the present study, the groundwater salinity of the Tabriz plain confined aquifer (i.e. in terms of EC) based on $\mathrm{Ca}^{2+}, \mathrm{Mg}^{2+}, \mathrm{Na}^{+}, \mathrm{SO}_{4}{ }^{2-}$ and $\mathrm{Cl}^{-}$concentrations was predicted by using MLP, RBFNN and GRNN neural networks and the concept of committee machine was employed to combine the advantages of individual neural networks. For these purposes, 93 data records collected from wells and after normalization of data set, the crossvalidation technique was used to divide the data sets as training and testing. After training and testing the ANN models, the performances of MLP, FFNN and GRNN models were compared and evaluated using RMSE, $\mathrm{R}^{2}$ and MARE. The RMSE, $\mathrm{R}^{2}$ and MARE values of the RBFNN model in the testing step were $342.5 \mu \mathrm{S} / \mathrm{cm}$, 0.985 and $8.71 \%$, respectively. The results indicated that the RBFNN model, among the individual used ANNs, showed the more accurate results. Finally, a committee neural network (CNN) was developed by means of genetic algorithm (GA). The committee neural network combines the results of salinity predicted from used ANNs; each of them has a weight factor showing its contribution in overall prediction. The GA derived
Table 3 Accuracy of the developed models for prediction of groundwater salinity in the training and testing step

\begin{tabular}{lllrlllr}
\hline Model & \multicolumn{2}{l}{ Training data set } & & \multicolumn{4}{l}{ Testing data set } \\
\cline { 2 - 3 } & $\mathrm{R}^{2}$ & RMSE $(\mu \mathrm{S} / \mathrm{cm})$ & MARE & & $\mathrm{R}^{2}$ & RMSE $(\mu S / \mathrm{cm})$ & MARE \\
\hline MLP & 0.995 & 171.02 & $11.38 \%$ & & 0.971 & 447.22 & $9.5 \%$ \\
RBFNN & 0.995 & 168.66 & $6.06 \%$ & & 0.985 & 342.5 & $8.71 \%$ \\
GRNN & 0.9877 & 270.65 & $15.22 \%$ & & 0.929 & 938.01 & $12.45 \%$ \\
CNN & 0.9972 & 129.94 & $5.51 \%$ & & 0.9908 & 317.86 & $4.38 \%$ \\
\hline
\end{tabular}



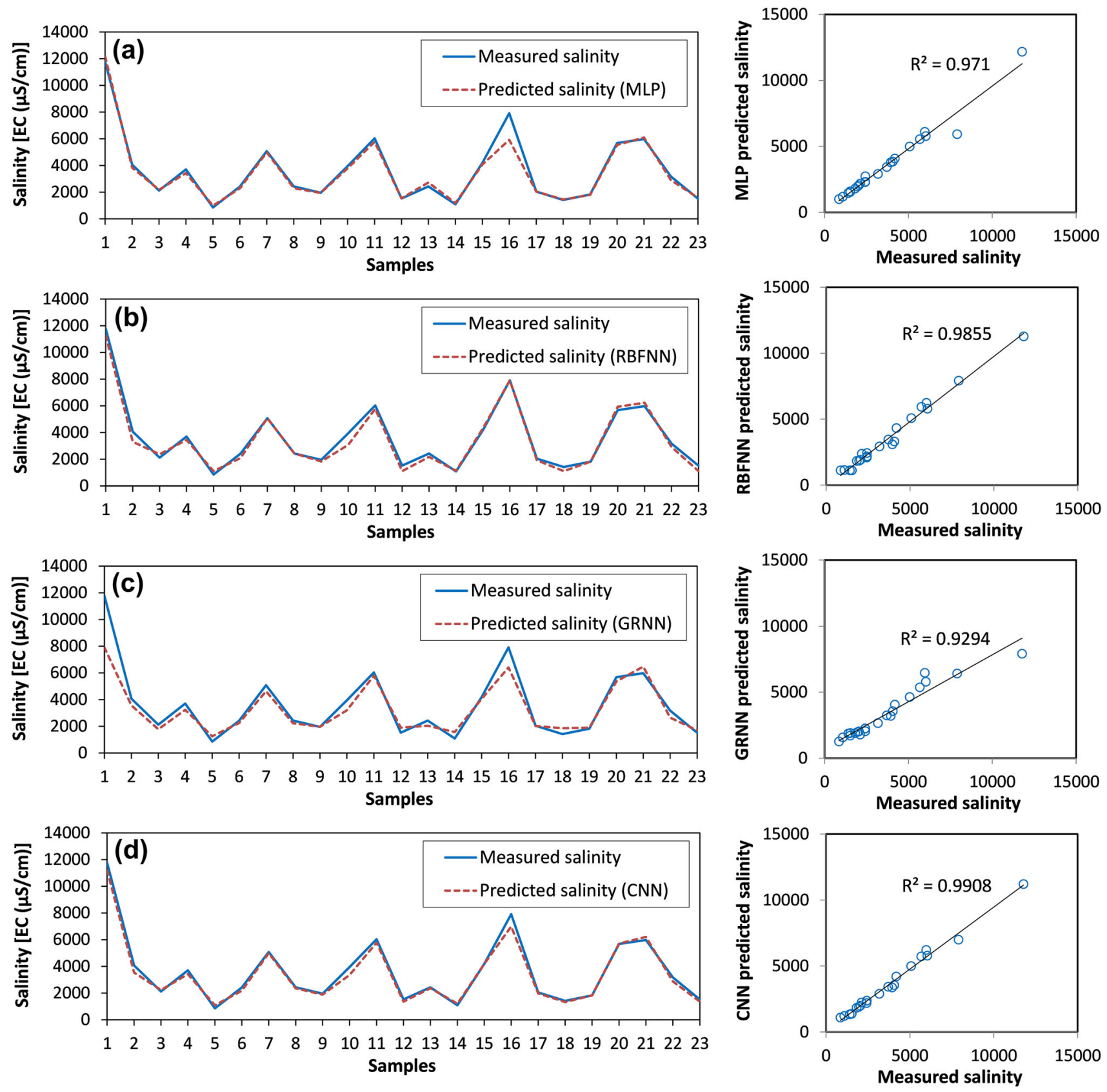

Fig. 10 Measured and predicted salinity $[\mathrm{EC}(\mu \mathrm{S} / \mathrm{cm})]$ for test samples using a MLP, b RBFNN, c GRNN and d CNN models

weights for MLP, RBFNN, and GRNN experts were 0.372 , 0.508 , and 0.12 , respectively. The RMSE, $\mathrm{R}^{2}$ and MARE values of the CNN model in the testing step were $317.86 \mu \mathrm{S} /$ $\mathrm{cm}, 0.9908$ and $4.38 \%$, respectively. A comparison between committee neural network and artificial neural networks indicates that committee neural network is capable of improving the accuracy of final salinity prediction.

Acknowledgments The authors are heartily thankful to Mr. Mortaza Najib for his kind helps and the East Azarbaijan Regional Water Company for data preparation.

\section{References}

Abid K, Zouari K, Dulinski M, Chkir N, Abidi B (2011) Hydrologic and geologic factors controlling groundwater geochemistry in the Turonian aquifer (southern Tunisia). Hydrogeol J 19:415-427

Alcalá FJ, Custodio E (2008) Atmospheric chloride deposition in continental Spain. Hydrol Process 22:3636-3650

Almasri MN (2007) Nitrate contamination of groundwater: a conceptual management framework. Environ Impact Assess Rev 27:220-242

Asghri Moghaddam A (1991) The hydrogeology of the Tabriz area, Iran. Ph.D. thesis, Department of geological Sciences, University College London 
Asghri Moghaddam A, Allaf Najib M (2006) Hydrogeologic characteristics of the alluvial tuff aquifer of northern Sahand Mountain slopes, Tabriz, Iran. Hydrogeol J 14(7):1319-1329

Bagheripour P (2014) Committee neural network model for rock permeability prediction. J Appl Geophys 104:142-148

Barzegar R (2014) The investigation of quantitative and qualitative of Tabriz plain aquifer groundwater resources. MSc. Thesis. Department of natural sciences, University of Tabriz

Barzegar R, Asghari Moghaddam A, Kazemian N (2015) Assessment of heavy metals concentrations with emphasis on arsenic in the Tabriz plain aquifers. Iran, Environ Earth Sci 74:297-313. doi:10.1007/s12665-014-4010-2

Ben Moussa A, Zouari K, Marc V (2011) Hydrochemical and isotope evidence of groundwater salinization processes on the coastal plain of Hammamet-Nabeul, north-eastern Tunisia. Phys Chem Earth 36:167-178

Bhatt A, Helle HB (2002) Committee neural networks for porosity and permeability prediction from well logs. Geophys Prospect 50:645-660

Bouchaou L, Michelot JL, Vengosh A, Hsissou Y, Qurtobi M, Gaye CB (2008) Application of multiple isotopic and geochemical tracers for investigation of recharge, salinization and residence time of water in the Souss-Massa aquifer, southwest of Morocco. J Hydrol 352(3-4):267-287

Broomhead D, Lowe D (1988) Multivariable functional interpolation and adaptive networks. Complex Syst 2(6):321-355

Celikoglu HB, Cigizoglu HK (2007) Public transportation trip flow modeling with generalized regression neural networks. Adv Eng Software 9:38-71

Chang FJ, Kao LS, Kuo YM, Liu CW (2010) Artificial neural networks for estimating regional arsenic concentrations in a blackfoot disease area in Taiwan. J Hydrol 388:65-76

Chang FJ, Tsai WB, Chen HK, Yam RSW, Herricks EE (2013) A self-organizing radial basis network for estimating riverine fish diversity. J Hydrol 476(1):280-289

Chen CH, Lin ZS (2006) A committee machine with empirical formulas for permeability prediction. Comput Geosci 32:485-496

Cigizoglu HK, Alp M (2006) Generalized regression neural network in modelling river sediment yield. Adv Eng Softw 8(37):63

Clair TA, Ehrman JM (1996) Variations in discharge and dissolved organic carbon and nitrogen export from terrestrial basins with changes in climate: a neural network approach. Limnol Oceanogr 41(5):921-927

Cruz JV, Coutinho R, Pacheco D, Cymbron R, Antunes R, Freire P (2011) Groundwater salinization in the Azores archipelago (Portugal). Environ Earth Sci 62:1273-1285

Custodio E (2010) Coastal aquifers of Europe: an overview. Hydrogeol J 18:269-280

Farber E, Vengosh A, Gavrieli I, Marie A, Bullen TD, Mayer B (2007) The geochemistry of groundwater resources in the Jordan Valley: the impact of the Rift Valley brines. Appl Geochem 22:494-514

Fernando DAK, Jayawardena AW (1998) Runoff forecasting using RBF networks with OLS algorithm. J Hydrol Eng 3(3):203-209

Fijani E, Nadiri AA, Asghari Moghaddam A, Tsai F, Dixon B (2013) Optimization of DRASTIC method by supervised committee machine artificial intelligence to assess groundwater vulnerability for Maragheh-Bonab plain aquifer. Iran, J hydrol 530:89-100

Firat M, Gungor M (2009) Generalized regression neural networks and feed forward neural networks for prediction of scour depth around bridge piers. Adv Eng Softw 40:731-737

García-Garizabal I, Causape J (2011) Influence of irrigation water management on the quantity and quality of irrigation return flows. J Hydrol 385:36-43
Ghavidel SZ, Montaseri M (2014) Application of different datadriven methods for the prediction of total dissolved solids in the Zarinehroud basin. Stoch Environ Res Risk Assess 28(8):2101-2118

Ghiasi-Freez J, Kadkhodaie-Ilkhchi A, Ziaii M (2012) Improving the accuracy of flow units prediction through two committee machine models: an example from the South Pars Gas Field, Persian Gulf Basin, Iran. Comput Geosci 46:10-23

Guan H, Love AJ, Simmons CT, Makhnin O, Kayaalp AS (2010) Factors influencing chloride deposition in a coastal hilly area and application to chloride deposition mapping. Hydrol Earth Syst Sci 14:801-813

Haykin S (1991) Neural networks: a comprehensive foundation. Prentice-Hall, Englewood Cliffs, p 842

Haykin S (1994) Neural networks a comprehensive foundation. Prentice Hall, Upper Saddle River

Huang W, Foo S (2002) Neural network modeling of salinity variation in Apalachicola River. Water Res 36:356-362

Jalali M (2007) Salinization of groundwater in arid and semi-arid zones: an example from Tajarak, western Iran. Environ Geol 52:1133-1149

Kadkhodaie-Ilkhchi A, Rezaee MR, Rahimpour-Bonab H (2009) A committee neural network for prediction of normalized oil content from well log data: an example from south pars gas field, Persian Gulf. J Pet Sci Eng 65:23-32

Karaca F, Ozkaya B (2006) NN-LEAP: a neural network-based model for controlling leachate flow-rate in a municipal solid waste landfill site. Environ Model Softw 21(8):1190-1197

Khashei-Siuki A, Sarbazi M (2013) Evaluation of ANFIS, ANN, and geostatistical models to spatial distribution of groundwater quality (case study: Mashhad plain in Iran). DOI, Arab J Geosci. doi:10.1007/s12517-013-1179-8

Kisi O (2007) Streamflow forecasting using different artificial neural network algorithms. J Hydrol Eng 12(5):532-539

Kisi O (2009) Daily pan evaporation modelling usingmulti-layer perceptrons and radial basis neural networks. Hydrol Process 23:213-223

Kisi O, Tombul M, Zounemat Kermani M (2015) Modeling soil temperatures at different depths by using three different neural computing techniques. Theor Appl Climatol 121(1):377-387

Kolay E, Baser T (2014) Estimating of the dry unit weight of compacted soils using general linear model and multi-layer perceptron neural networks. Appl Soft Comput 18:223-231

Lim JS (2005) Reservoir properties determination using fuzzy logic and neural networks from well data in offshore Korea. J Petrol Sci Eng 49:182-192

Maier HR, Dandy GC (1996) The use of artificial neural networks for the prediction of water quality parameters. Water Resour Res 32(4):1013-1022

Maqsood I, Khan MR, Huang GH, Abdalla R (2005) Application of soft computing models to hourly weather analysis in southern Saskatchewan, Canada. Eng Appl Artif Intell 18:115-125

Nadiri AA, Chitsazan N, Tsai FT, Moghaddam AA (2014) Bayesian artificial intelligence model averaging for hydraulic conductivity estimation. J Hydrol Eng 19:520-532

Nasr M, Zahran HF (2014) Using of pH as a tool to predict salinity of groundwater for irrigation purpose using artificial neural network. Egypt J Aquat Res 40:111-115

Nourani V, Baghanam AH, Adamowski J, Gebremichael M (2013) Using self-organizing maps and wavelet transforms for spacetime pre-processing of satellite precipitation and runoff data in neural network based rainfall-runoff modeling. J Hydrol 476:228-243

Oren O, Yechieli Y, Bohlke JK, Dody A (2004) Contamination of groundwater under cultivated fields in an arid environment, central Arava Valley, Israel. J Hydrol 290:312-328 
Park SC, Yuna ST, Chaea GT, Yooa IS, Shina KS, Heoa CH (2005) Regional hydrochemical study on salinization of coastal aquifers, western coastal area of South Korea. J Hydrol 313:182-194

Ravansalar M, Rajaee T (2015) Evaluation of wavelet performance via an ANN-based electrical conductivity prediction model. Environ Monit Assess. doi:10.1007/s10661-015-4590-7

Rodriguez MJ, Serodes JB (1998) Assessing empirical linear and nonlinear modelling of residual chlorine in urban drinking water systems. Environ Model Softw 14(1):93-102

Rojas R (1996) Neural networks: a systematic introduction. SpringerVerlag, Berlin, pp 149-182

Seyyed AM, Gholamm AK, Zeynab P, Zeynab B, Mohammad S (2013) Estimate the spatial distribution TDS the fusion method Geostatistics and artificial neural networks. Inter J Agric Crop Sci. 6(7):410-420
Sharkey AJC (1996) On combining artificial neural networks. Connect Sci 8:299-314

Tayfur G, Nadiri AA, Moghaddam AA (2014) Supervised intelligent committee machine method for hydraulic conductivity estimation. Water Resour Manage 28:1173-1184

Van der Weijden CH, Pacheco FAL (2003) Hydrochemistry, weathering and weathering rates on Madeira Island. J Hydrol 283:122-145

Yesilnacar MI, Sahinkaya E, Naz M, Ozkaya B (2008) Neural network prediction of nitrate in groundwater of Harran Plain, Turkey. Environ Geol 56:19-25

Yesilnacar MI, Sahinkaya E, Naz M (2012) Artificial neural network prediction of sulfate and SAR in an unconfined aquifer in southeastern Turkey. Environ Earth Sci 67:1111-1119 